\title{
Evaluation of multi-temporal and multi-sensor atmospheric correction strategies for land cover accounting and monitoring in Ireland
}

\author{
Christoph Raab $^{\mathrm{a} *}$, Brian Barrett ${ }^{\mathrm{ab}}$, Fiona Cawkwell ${ }^{\mathrm{a}}$, Stuart Green ${ }^{\mathrm{c}}$ \\ ${ }^{a}$ School of Geography \& Archaeology, University College Cork (UCC), Republic of Ireland \\ ${ }^{b}$ School of Geographical \& Earth Sciences, University of Glasgow, Scotland, UK. \\ ${ }^{c}$ Teagasc, Ashtown, Dublin 15, Irish Agriculture and Food Development Authority, Republic \\ of Ireland
}

* Corresponding author: christoph.raab@ucc.ie

\begin{abstract}
Accurate atmospheric correction is an important pre-processing step for studies of multitemporal landcover mapping using optical satellite data. Model-based surface reflectance predictions (e.g. 6S - Second Simulation of Satellite Signal in the Solar Spectrum) are highly dependent on the adjustment of aerosol optical thickness (AOT) data. For regions with no or insufficient spatial and temporal coverage of meteorological ground measurements, MODIS derived AOT data are a valuable alternative, especially with regard to the dynamics of atmospheric conditions. In this study, atmospheric correction strategies were assessed based on the change in standard deviation $(\sigma)$ compared to the raw data and also by machine learning landcover classification accuracies. For three Landsat 8 OLI (acquired in 2013) and two RapidEye (acquired in 2010 and 2014) scenes, seven different correction strategies were tested over an agricultural area in south-east Ireland. Visibility calculated from daily spatial averaged TERRA-MODIS estimates $\left(1^{\circ} \times 1^{\circ}\right.$ Aerosol Product) served as input for the atmospheric correction. In almost all cases the standard deviation of the raw data is reduced after incorporation of terrain correction, compared to the atmospheric corrected data. ATCOR®-IDL based correction decreases the standard deviation almost consistently (ranging from -0.3 to 26.7). The 6S implementation in GRASS GIS showed a tendency of increasing the variation in the data, especially for the RapidEye data. No major differences in overall accuracies and Kappa values were observed between the three machine learning classification approaches. The results indicate that the ATCOR®-IDL based correction and MODIS parametrisation methods are able to decrease the standard deviation and are therefore an appropriate approach to approximate the top-of-canopy reflectance.
\end{abstract}


Keywords: Atmospheric correction, Topographic correction, Aerosol optical thickness, Machine learning, Landsat OLI, RapidEye

\section{Introduction}

The electromagnetic radiation recorded by earth observation (EO) satellites is influenced by a composition of gases and aerosols in the atmosphere, due to scattering and absorption (Song et al. 2001). For the analysis of multi-temporal landcover patterns it is essential to reduce this effect, in order to obtain comparable surface reflectance values. In contrast to simple imagebased correction methods, such as dark object subtraction (DOS) (Chavez 1988), radiative transfer models are designed to approximate the atmospheric conditions at the time of image acquisition. The Second Simulation of Satellite Signal in the Solar Spectrum (6S) (Vermote et al. 1997) and MODerate resolution atmospheric TRANsmission (MODTRAN®5) (Berk et al. 2006) models are widely used and accepted for estimating the propagation of electromagnetic radiation in the atmosphere (Mahiny and Turner 2007; Balthazar et al. 2012; Burns and Nolin 2014; Mannschatz et al. 2014). Both models are dependent on and highly influenced by the parametrisation of aerosol optical thickness (AOT) $\left(\tau_{\alpha}\right)$, a dimensionless measure to quantify the degree of restriction of the electromagnetic transmission in the atmosphere (Mannschatz et al. 2014). One of the most reliable sources of AOT data is given by the global Aerosol Robotic Network (AERONET) records (Holben et al. 1998; Holben et al. 2001). AERONET based atmospheric correction models are reported to achieve errors of less than 2\% (Ju et al. 2012) and have been applied for validation of EO surface reflectance data (Vermote et al. 2002; Kotchenova et al. 2006). However, in regions where the distance to the nearest station is large, the validity of measured ground data decreases rapidly, due to the spatially non-uniform composition of the atmosphere (Wilson et al. 2014). At the moment, there is no active AERONET station in Ireland and historical measurements for Mace Head are only available for seven days in 2003 and 2004. Given this circumstance, an 
alternative data source can be provided by aerosol estimates provided by EO missions, such as the MODIS sensors (Ju et al. 2012; Burns and Nolin 2014). According to Chu et al. (2002) MODIS AOT data can be found within a retrieval error range $\left(\Delta \tau_{a}\right)$ of $\Delta \tau_{a}= \pm 0.05 \pm$ $0.2 \tau_{\alpha}$ compared to more than 30 AERONET stations, with a root mean square (RMS) error up to 0.3 in coastal regions, mainly due to water contaminated signals. In an independent validation of MODIS AOT data by Levy et al. (2010), 66\% of the retrievals were in an expected error range of $\pm 0.05+0.15 \%(R=0.9)$, compared to AERONET measurements at over 300 sites. Ju et al. (2012) validated a MODIS-based and Landsat Ecosystem Disturbance Adaptive Processing System (LEDPAS) atmospheric correction strategy for Landsat ETM+ data on a continental scale over 26 AERONET station across the United Sates. A total of 82 acquisitions indicate that the MODIS-based approach reveals more accurate results in the red and longer wavelength bands than the image-based LEDPAS correction. An additional AOT data source can be provided by the multi-sensor GlobAerosol product (Wilson et al. 2014). After a quality assessment, the data of ATSR-2, AATSR, MERIS and SEVERI are merged using temporal interpolation (Thomas et al. 2010), however the advantage of an enhanced spatial coverage is offset by an increased error (Poulsen et al. 2009).

In this study, visibilities $(V)$ calculated in kilometres $(\mathrm{km})$ from daily spatial averaged TERRA-MODIS estimates $\left(1^{\circ} \times 1^{\circ}\right.$ Aerosol Product $)$ were used to evaluate the performance of different atmospheric correction strategies. The aim was to compare the MODTRAN®5 correction model implemented in ERDAS IMAGINE® and ATCOR-IDL® with results from the $6 \mathrm{~S}$ algorithm (implemented in the open source GRASS GIS 7.0.0) and newly available Landsat 8 Surface Reflectance (L8SR 0.2.0) data, based on both classification accuracies and the characterisation of standard deviations. The raw image data is used as reference quantity in both sets of analysis, based on the assumption of a decrease in standard deviation after the reduction of signal distortions by the atmosphere and terrain. 


\section{Methods}

\subsection{Study area and classification schema}

The River Suir catchment is situated in the southeast of Ireland and covers an area of approximately $3600 \mathrm{~km}^{2}$ with altitudes ranging from near zero up to about 915 metres above sea level (Figure 1). The predominantly rural landcover is characterised by arable and pastoral land in the lowland areas. The upland areas, such as the Comeragh and Galtee mountains are associated with large areas of semi-improved grassland, heath and peatland, forming living space for several priority Annex 1 habitats under the EU Habitats Directive (Council Directive 92/43/EEC); active blanket bog and species-rich Nardus grassland, along with European dry heath, alpine and boreal heath, and oligotrophic standing waters among others. The temperate oceanic climate is characterised by a mean annual precipitation of $1029 \mathrm{~mm}$ and a mean temperature of $9.9^{\circ} \mathrm{C}$, measured at the nearest synoptic weather station at Fermoy (Moorepark) in County Cork; approximately $15 \mathrm{~km}$ south-west from the investigation area.

\section{[FIGURE 1]}

\subsection{Satellite Data}

Three Landsat 8 Level 1T scenes covering the dates 9 June (one scene - Path/Row 207/023) and 20 July 2013 (two scenes - Path/Row 206/023 and 206/024) as well as the surface reflectance L8SR 0.2.0 data were obtained. Additionally, cloud-free RapidEye Level 3A scenes from 11 April 2010 and 10 March 2014 were acquired, covering an area of $625 \mathrm{~km}^{2}$ in the southeast of the investigation area (Comeragh mountains). A NextMap® 5m DEM for the study site served as high resolution elevation data. Daily spatially averaged TERRA-MODIS AOT values at $550 \mathrm{~nm}\left(1^{\circ} \times 1^{\circ}\right.$ Aerosol Product $)$ were obtained for the investigation area 
according to the respective image acquisition date from Acker and Leptoukh (2007). The MOD08_D3 product is based on the latest version of the production algorithm (5.1), which forms a daily global product containing a range of scientific parameters, such as aerosol, water, vapour, cloud and atmosphere profile (Level-2) (Hubanks et al. 2008).

\subsubsection{Pre-processing}

Cloud cover is one of the major limitations in successfully using optical remote sensing in Ireland (Nitze et al. 2015), and cloud shadows can further lead to distortions of the surface reflectance recorded by the sensor. As a result, all Landsat 8 scenes were masked according to the buffered result provided by the cloud screening tool Fmask (Zhu and Woodcock 2012) and clipped according to the Suir catchment extent (see Figure 1). For the MODTRAN®5 implementation in ATCOR®, the AOT must be adjusted by $V$ in kilometres $(\mathrm{km})$. This nonlinear relationship is formulised by Richter and Schläpfer (2013) as:

$$
A O T=e^{a(z)+b(z) \times \ln (V)}
$$

Based on the daily spatially averaged TERRA-MODIS AOT values in Table 1, the mean elevation $(E)$ for the particular area in kilometres $(\mathrm{km})$ and the regression equations for $a(z)$ and $b(z)$ outlined by Richter (2014), it was possible to derive acquisition dependent $V$ (equations (2) and (3)):

$$
\begin{array}{ll}
a(z)=-0.2516 \times E-1.5613 & R^{2}=0.9968 \\
b(z)=0.0198 \times E-0.8558 & R^{2}=0.9927
\end{array}
$$

As a final step, the two Landsat 8 acquisitions from 20 July 2013 were mosaicked according to the mean value approach, after the particular atmospheric or topographic correction procedure. The aim was to gain a full coverage for the multi-temporal classification. 


\section{[TABLE 1]}

\subsubsection{Atmospheric and topographic correction}

A strong influence, in classification accuracy, is observed in mountainous areas where the slopes are oriented away from and towards the illumination by the sun, appearing darker and brighter respectively (Richter et al. 2009). Due to this, the same surface cover can be classified differently, which can cause an incorrect result. The different implementations of ATCOR $®$ enable the correction of multispectral remote sensing data over flat terrain (ATCOR ${ }^{2}$ ) as well as rugged terrain $(\mathrm{ATCOR} ® 3)$. The core difference is that the topographic correction in ATCOR $® 3$ models the illumination conditions at the time of data acquisition based on terrain data and position of the sun and EO sensor. The aim of the topographic correction strategies is therefore to decrease the standard deviation for a respective class and to improve the stability of multi-temporal comparisons and change detection (Hantson and Chuvieco 2011). The Minnaert (Minnaert 1941) correction assumes a Lambertian surface which is further approximated to a non-Lambertian surface by a model based factor. The empirical-statistical C-Factor (Teillet et al. 1982) approach is based on the assumed relationship of the terrain illumination and surface reflectance, requiring a DEM as explained in detail in Riaño et al. (2003). The C-Factor correction strategy is ranked by a large number of studies as robust in terms of overall accuracy and/or reduction of standard deviation (Riaño et al. 2003; Vicente-Serrano et al. 2008; Richter et al. 2009; Hantson and Chuvieco 2011; Vanonckelen et al. 2013), and is therefore included as the terrain correction method in this study for the $6 \mathrm{~S}$ approach.

The parametrisation of the applied correction models was adjusted according to the metadata and based on the required aerosol and atmosphere types as outlined in Table 2. Moreover, the sensor and band dependent radiometric rescaling factors were extracted, for input to each of the MODTRAN®5 implementations. Landsat OLI top of atmosphere 
reflectance (TOA) was calculated according to USGS (2015), and RapidEye TOA was derived as given in the Product Specifications (BlackBridge 2015).

[TABLE 2]

In preparation of the ATCOR $®$ based correction, slope and aspect, skyview and cast shadow data files were derived from the DEM by the respective tool in ATCOR-IDL® and ERDAS IMAGINE®. Subsequently, adjacency range $(1 \mathrm{~km})$ and ozone value (331) were set to default and no bidirectional reflectance distribution function (BRDF) was applied. Table 3 shows an example of an input parameter file used for the $6 \mathrm{~S}$ atmospheric correction in GRASS GIS. Since $V$ values up to $120 \mathrm{~km}$ are accepted in both MODTRAN@5 implementations, the parameter for the RapidEye scene 10 March 2014 was adjusted accordingly. The topographic influence was reduced for the $6 \mathrm{~S}$ model with the C-correction method, as implemented in the i.topo.corr function in GRASS GIS (GRASS Development Team 2015).

[TABLE 3]

\subsection{Classification and comparison}

The performance of the different correction strategies was evaluated based on machine learning classification accuracy measures and change in standard deviation compared to the raw data. Three non-parametric classifiers; Support Vector Machines (SVM), Random Forests (RF) and Extremely Randomised Trees were applied to the multi-temporal Landsat 8 dataset using the open-source Scikit-learn module (Pedregosa et al. 2011) in Python 2.7.6, similar to the approach discussed by Barrett et al. (2014) and Nitze et al. (2015). Before the standard deviations were obtained, all data (Landsat 8 and RapidEye) were normalised to the range $0-1000$

The applied classification schema consists of eight classes in line with the broad-scale 
habitat classification scheme of Fossitt (2000), including water, grassland, heath \& dense bracken, peat land, woodland \& scrub, exposed, built and arable land. Facilitated by ancillary data, training and validation data preparation for the initial multi-temporal Landsat 8 landcover classification followed a stratified random sampling approach. The Irish Land Parcel Identification System (LPIS), Forest Inventory and Planning System (FIPS), National Survey of Upland Habitats (NSUH) field survey for Galtee and Comeragh mountains as well as Microsoft ${ }^{\circledR}$ Bing Imagery aided this process.

\section{Results and Discussion}

The results indicate only marginal differences between the different correction strategies in terms of overall accuracies (OA), ranging from $86.3 \%$ (RF and $6 \mathrm{~S}$ and C-correction combined) up to $91.0 \%$ (ERT ATCOR®2 ERDAS® and Raw data), as summarised in Figure 2. The ERT classifier outperforms SVM and RF in most of the cases, which is

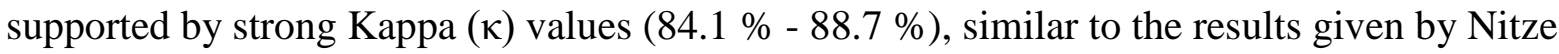
et al. (2015). All three classifiers revealed lowest OA and $\kappa$ values for the combination of $6 \mathrm{~S}$ and C-correction, whereby the highest values are given for $6 \mathrm{~S}$ itself and IDL based correction, as well as ATCOR®2 in ERDAS®. For the raw data, OA above $90 \%$ and $\kappa$ $\geq 88 \%$ are recorded, respectively.

\section{[FIGURE2]}

The results of changes in standard deviation compared to the raw data after atmospheric and terrain correction are outlined in Figure 3 for Landsat OLI and in Figure 4 for RapidEye. 6S increases the standard deviation for all bands in almost all cases, with exceptions for Landsat OLI on 20 July 2013. The subsequent C-correction decreases the $\sigma$ for both sensors and all bands, with extreme results for the IR band of RapidEye (-81.3 for 10 March 2014 of the NIR band) and Landsat OLI (-99.6 for 9 June 2013 of the NIR and -83.2 
for 20 July 2013 of the SWIR2 band). Based on insufficient elevation data, Burns and Nolin (2014) excluded the C-factor correction for the final product during the examination of glacier area change in Peru from 1987 to 2010. To improve the topographic correction, Hantson and Chuvieco (2011) suggested a landcover dependent or NDVI threshold based topographic correction using the regression between illumination and reflectance of the Ccorrection method.

The IDL based ATCOR®2 and ATCOR®3 implementation decreases the dispersion consistently, with highest reduction of $\sigma$ for RapidEye at 20 March 2014. In general, the $\sigma$ decreases after considering the terrain (IDL- ATCOR®3) compared to the flat terrain option (IDL- ATCOR $® 2)$. The change in $\sigma$ for ATCOR $® 2$ in ERDAS $®$ is similar to the IDL based counterpart, whereby the ATCOR $® 3$ option revealed an increase and only for Landsat OLI at 20 July 2013 in a decrease of $\sigma$ for all bands. The provisional Landsat 8 Surface Reflectance product tends to increase the dispersion (ranging from 0.1 to 7.5 ), with exceptions for the IR for Landsat OLI at 20 July 2013. In general the impact on the $\sigma$ for the L8SR is low.

\section{[FIGURE3]}

\section{[FIGURE4]}

Since all analysed strategies apply the correction of the atmospheric influence to all pixels based on one $V$ value, and thereby not taking spatial variations into account, it is likely that the covariance of the classes is not altered (Wilson et al. 2014). This reflects to some extent the small variations of $\mathrm{OA}$ and $\kappa$ for the different correction strategies, tested for three different machine learning classification algorithms. Moreover, as indicated by the feature importance of the RF model, the Landsat OLI acquisition from 20 July 2013 contributes much more to the classification than the June image. Hence, the impact of the atmospheric correction is low. As outlined by Lu et al. (2002), the impact of aerosol particle scattering on the NIR and SWIR part of the electromagnetic spectra is negligible, and it is mainly 
influenced by absorption due to water vapour and other gases. Conversely, the visible bands of earth observation data are largely affected by Rayleigh and aerosol scattering. The major increase in standard deviation after the $6 \mathrm{~S}$ correction for the IR part of both sensors can be explained by the non-consideration of acquisition dependent water vapour and other atmospheric gases. However, when comparing different correction strategies Richter et al. (2009) pointed out that no best technique can necessarily be proven since the results may change with regard to area of interest and scale.

\section{Conclusion}

The parametrisation of $V$ by MODIS derived Aerosol Optical Thickness estimates is presented as a suitable strategy for atmospheric correction, in regions with no or insufficient ground-based measurements. However, there are historical limitations in the archive as well as data inconsistency due to cloud contaminations. The preliminary results indicate that all analysed atmospheric correction strategies revealed high OA $(86.3 \%-91.0 \%)$ and $\kappa$ values $(84.1 \%-88.7 \%)$. The low accuracies for $6 \mathrm{~S}$ combined with the C-correction are in line with the observed extreme in decreases of standard deviation (up to -99.6 compared to the raw data). There is no major effect on $\mathrm{OA}$ and $\kappa$ between $6 \mathrm{~S}$ without applied topographic correction and MODTRAN®5 based ATCOR®2 and ATCOR®3 correction strategies. However, the ATCOR ${ }^{\circledR} 3$ version of ERDAS $®$ revealed marginally lower OA and $\kappa$ values compared to the ATCOR2-ERDAS® and the IDL based version. This reflects the inconsistent change in $\sigma$ between ATCOR $₫ 2$ and ATCOR $® 3$ of ERDAS $₫$ as shown in Figure 3 and Figure 4. The change in standard deviation of the provisional Landsat 8 surface reflectance product indicates that the data modification is much lower than for all other correction strategies. Based on this, the IDL based ATCOR® correction strategy can be seen as very robust. For a more reliable evaluation of the different correction strategies, ground 
measurements of reflectance values should be considered.

In addition, more effort should be made in order to test the performance of the $6 \mathrm{~S}$ implementation in GRASS GIS with regard to non-predefined atmospheric models. All tested atmospheric and topographic correction strategies represent a modification of the raw image and affect the distribution of the data, which can lead to confusion and change in overall accuracies when the data are used for classification. For a robust investigation on the effect of AOT parametrisation on the different correction strategies further research is required. For this, a more detailed knowledge of different landcover classes in terms of standard deviation and classification accuracy is recommended. The calibration of MODIS derived AOT estimates by ground-based meteorological measurements to enable a global cover of $V$ values for atmospheric correction could therefore further improve the approximation of surface reflectance in the future. Moreover, if no atmospheric correction can be performed by the user, the L8SR data can be seen as a reliable alternative.

\section{Acknowledgements}

This study was funded by the Environmental Protection Agency (EPA) under the Science, Technology, Research and Innovation for the Environment (STRIVE) programme 2007 2013. The authors would like to thank the National Parks and Wildlife Service (NPWS) for providing the field survey data from the National Survey of Upland Habitats (NSUH) programme and also the Department of Agriculture, Food and the Marine for providing Forest Inventory and Planning System (FIPS) data. Moreover, we would like to thank the European Space Agency (ESA) for providing the satellite data through Cat-1 proposal ID 28407. 


\section{References}

ACKER, J.G. and LEPTOUKH, G., 2007, Online analysis enhances use of NASA earth science data. Eos, Transactions American Geophysical Union 88 (2), pp.14-17. doi:10.1117/12.665077

BALTHAZAR, V., VANACKER, V. and LAMBIN, E.F., 2012, Evaluation and parameterization of ATCOR3 topographic correction method for forest cover mapping in mountain areas. International Journal of Applied Earth Observation and Geoinformation, 18, pp. 43650. doi:10.1016/j.jag.2012.03.010

Barrett, B., Nitze, I., Green, S. and CAWKwell, F., 2014. Assessment of multi-temporal, multi-sensor radar and ancillary spatial data for grasslands monitoring in Ireland using machine learning approaches. Remote Sensing of Environment, 152, pp.109-24. doi: 10.1016/j.rse.2014.05.018

Berk, A., Anderson,G.P., Acharya, P.K., Bernstein, L.S., Muratov, L. et al, 2006. Proc. SPIE 6233, Algorithms and Technologies for Multispectral, Hyperspectral, and Ultraspectral Imagery XII, pp. 62331F-62331. doi:10.1117/12.665077

BlACKBRIDGE, 2015, Satellite Imagery Product Specification. 6.1, pp. 1-48. http://blackbridge.com/rapideye/upload/RE_Product_Specifications_ENG.pdf (last accessed 21 July 2015).

BuRns, P. and Nolin, A., 2014, Using atmospherically-corrected Landsat imagery to measure glacier area change in the Cordillera Blanca, Peru from 1987 to 2010. Remote Sensing of Environment, 140, pp.165-78. doi: 10.1016/j.rse.2013.08.026

CHAVEZ, P.S., 1988, An improved dark-object subtraction technique for atmospheric scattering correction of multispectral data. Remote Sensing of Environment, 24 (3), pp. 459-79. doi: 10.1016/0034-4257(88)90019-3

FossitT, J.A., 2000. A guide to habitats in Ireland. Heritage Council/Chomhairle Oidhreachta (Kilkenny). http://www.heritagecouncil.ie/fileadmin/user_upload/Publications/Wildlife/Guide_to_ Habitats.pdf (last accessed 21 July 2015).

GRASS DeVelopment Team, 2015. Geographic Resources Analysis Support System (GRASS) Software. Version 7.0. Open Source Geospatial Foundation. http://grass.osgeo.org/ (last accessed 21 July 2015). 
HANTson, S. and ChUviECO, E., 2011. Evaluation of different topographic correction methods for Landsat imagery. International Journal of Applied Earth Observation and Geoinformation, 13 (5), pp. 691-700. doi: 10.1016/j.jag.2011.05.001

Holben, B.N., Eck, T.F., Slutsker, I., TAnre, D., Buis, J.P., Setzer, A., Vermote, E., ReAgan, J.A., KAUfMan, Y.J. and NAKAJIMA, T. et al., 1998. AERONET-A federated instrument network and data archive for aerosol characterization. Remote Sensing of Environment, 66 (1), pp. 1-16. doi: 10.1016/S0034-4257(98)00031-5

Holben, B.N., TAnre, D., Smirnov, A., Eck, T.F., Slutsker, I., Abuhassan, N., Newcomb, W.W., Schafer, J.S., Chatenet, B. and Lavenu, F. et al. 2001. An emerging ground-based aerosol climatology: Aerosol optical depth from AERONET. Journal of Geophysical Research: Atmospheres (1984-2012),106 (D11), pp.1206797. doi: 10.1029/2001JD900014

Hubanks, P.A., King, M.D., Platnick, S. and Pincus, R., 2008. MODIS atmosphere L3 gridded product algorithm theoretical basis document. NASA Goddard Space Flight Cent., Greenbelt, Md.

http://modis-atmos.gsfc.nasa.gov/_docs/L3_ATBD_2008_12_04.pdf (last accessed 21 July 2015).

Ju, J., Roy, D.P., Vermote, E., Masek, J. and Kovalskyy, V., 2012. Continental-scale validation of MODIS-based and LEDAPS Landsat ETM+ atmospheric correction methods. Remote Sensing of Environment, 122, pp. 175-84. doi:

10.1016/j.rse.2011.12.025

Kotchenova, S.Y., Vermote, E.F., Matarrese, R. and Klemm, F.J. Jr., 2006. Validation of a vector version of the $6 \mathrm{~S}$ radiative transfer code for atmospheric correction of satellite data. Part I: Path radiance. Applied optics, 45 (26), pp. 6762-74. doi: 10.1364/AO.45.006762

Lu, D., Mausel, P., Brondizio, E. and Moran, E., 2002. Assessment of atmospheric correction methods for Landsat TM data applicable to Amazon basin LBA research. International Journal of Remote Sensing, 23 (13), pp. 2651-71. doi: $10.1080 / 01431160110109642$

MAHINY, A.S and TURNER, B.J., 2007. A comparison of four common atmospheric correction methods. Photogrammetric Engineering \& Remote Sensing, 73 (4), pp. 361-8. doi: http://dx.doi.org/10.14358/PERS.73.4.361 
Mannschatz, T., Pflug, B., Borg, E., Feger, K.-H. and Dietrich, P., 2014. Uncertainties of LAI estimation from satellite imaging due to atmospheric correction. Remote Sensing of Environment, 153, pp. 24-39. doi: 10.1016/j.rse.2014.07.020

MinnAERT, M., 1941. The reciprocity principle in lunar photometry. The Astrophysical Journal, 93, pp. 403-10.

Nitze, I., BARRett, B. and CAWKwEll, F., 2015. Temporal optimisation of image acquisition for land cover classification with Random Forest and MODIS time-series. International Journal of Applied Earth Observation and Geoinformation, 34, pp. 13646. doi: 10.1016/j.jag.2014.08.001

Pedregosa, F., Varoquaux, G., Gramfort, A., Michel, V., Thirion, B., Grisel, O., Blondel, M., Prettenhofer, P., Weiss, R. and Dubourg, V., 2011. Scikit-learn: Machine learning in Python. The Journal of Machine Learning Research, 12, pp. 2825-30.

Poulsen, C.A., Siddans, R., Thomas, G.E., SAyer, A., Grainger, R.G., Perez-Navarro, O., Portela-ArJona, O. and Yves-Deschamps, P., 2009. ESA GlobAerosol: Final validation and intercomparison report, version 3.2, technical report, European Space Agency (Paris).

Riaño, D., Chuvieco, E., Salas, J. and Aguado, I., 2003. Assessment of different topographic corrections in Landsat-TM data for mapping vegetation types. Geoscience and Remote Sensing, IEEE Transactions on, 41 (5), pp. 1056-61. doi: 10.1109/TGRS.2003.811693

RICHTER, R., 2014. Aerosol Optical Thickness and visibility. Personal communication (1 December 2014).

RICHTER, R, and SCHLÄPFER, D., 2015. Atmospheric/Topographic Correction for Satellite Imagery (ATCOR-2/3 User Guide, Version 9.0.0, June 2015). Report DLR-IB 56501/15. http://atcor.com/pdf/atcor3_manual.pdf (last accessed 21 July 2015).

Richter, R., Kellenberger, T. and Kaufmann, H., 2009. Comparison of topographic correction methods. Remote Sensing 1 (3), pp. 184-96. doi: 10.3390/rs1030184

Teillet, P.M., Guindon, B. and Goodenough, D.G., 1982. On the slope-aspect correction of multispectral scanner data. Canadian Journal of Remote Sensing, 8 (2), pp. 84-106. doi: $10.1080 / 07038992.1982 .10855028$

Thomas, G., Poulsen, C., Siddans, R., Carboni, E., SAyer, A. and Grainger, D., 2010. The GlobAEROSOL dataset: Using a multi-instrument satellite aerosol dataset. $E G U$ General Assembly Conference Abstracts, 12, p. 11081. 
USGS, 2015. Using the USGS Landsat 8 Product. http://landsat.usgs.gov/Landsat8_Using_Product.php (last accessed 21 July 2015).

VAnonckelen, S., Lhermitte, S. and VAn Rompaey, A., 2013. The effect of atmospheric and topographic correction methods on land cover classification accuracy. International Journal of Applied Earth Observation and Geoinformation, 24, pp. 921. doi: 10.1016/j.jag.2013.02.003

Vermote, E.F., Tanre, D., Deuze, J.L., Herman, M. and Morcette, J.J.. 1997. Second Simulation of the Satellite Signal in the Solar Spectrum, 6S: an overview. Geoscience and Remote Sensing, IEEE Transactions on, 35 (3), pp. 675-86. doi: $10.1109 / 36.581987$

Vermote, E.F., El SAleous, N.Z. and Justice, C.O, 2002. Atmospheric correction of MODIS data in the visible to middle infrared: first results. Remote Sensing of Environment, 83 (1), pp. 97-111. doi: 10.1016/S0034-4257(02)00089-5

Vicente-Serrano, S.M., PÉrez-Cabello, F. and Lasanta, T., 2008. Assessment of radiometric correction techniques in analyzing vegetation variability and change using time series of Landsat images. Remote Sensing of Environment, 112 (10), pp. 391634. doi: 10.1016/j.rse.2008.06.011

WiLson, R. T., Milton, E. J. and NiELD, J. M., 2014. Spatial variability of the atmosphere over southern England, and its effect on scene-based atmospheric corrections. International Journal of Remote Sensing, 35 (13), pp. 5198-218. doi: $10.1080 / 01431161.2014 .939781$

ZHU, Z. and WoODCOCK, C.E, 2012. Object-based cloud and cloud shadow detection in Landsat imagery. Remote Sensing of Environment, 118, pp. 83-94. doi: 


\section{List of Tables}

Table 1. Acquisition dependent parameter for $V$ calculation.

\begin{tabular}{cccccc}
\hline & $\begin{array}{c}E \\
(\mathbf{k m})\end{array}$ & $\mathbf{a}(\mathbf{z})$ & $\mathbf{b}(\mathbf{z})$ & $\begin{array}{c}\text { AOT } \\
\text { Terra }\end{array}$ & $\begin{array}{c}V \\
(\mathbf{k m})\end{array}$ \\
\hline Landsat 8 09 June 2013 & 0.137 & 1.5268 & -0.8531 & 0.131 & 64.9 \\
Landsat 8 20 July 2013 & 0.137 & 1.5268 & -0.8531 & 0.141 & 59.5 \\
RapidEye 11 April 2010 & 0.133 & 1.5278 & -0.8532 & 0.136 & 62.1 \\
RapidEye 10 March 2014 & 0.133 & 1.5278 & -0.8532 & 0.05 & 200.8 \\
\hline
\end{tabular}

Table 2. Atmospheric correction model and parametrisation

\begin{tabular}{|c|c|c|c|c|c|c|}
\hline & \multirow{2}{*}{$\begin{array}{l}\text { Product } \\
\text { Date }\end{array}$} & \multirow{2}{*}{$\begin{array}{c}\text { LC8206024 } \\
20 \text { July } 2013\end{array}$} & \multirow{2}{*}{$\begin{array}{c}\text { LC8206023 } \\
\text { 20 July } 2013\end{array}$} & \multirow{2}{*}{$\begin{array}{c}\text { LC8207023 } \\
09 \text { June2013 }\end{array}$} & \multirow{2}{*}{$\begin{array}{c}\text { RE2963219 } \\
10 \text { March } 2014\end{array}$} & \multirow{2}{*}{$\begin{array}{c}\text { RE2963217 } \\
11 \text { April } 2010\end{array}$} \\
\hline & & & & & & \\
\hline \multirow{4}{*}{ 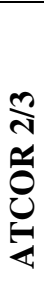 } & Aerosol Type & maritime & maritime & maritime & maritime & maritime \\
\hline & Water & mid-latitude & mid-latitude & mid-latitude & fall-spring & fall-spring \\
\hline & Vapour & summer & summer & summer & maritime & maritime \\
\hline & Category & & & & & \\
\hline \multirow{3}{*}{ 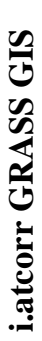 } & Atmospheric & maritime & maritime & maritime & maritime & maritime \\
\hline & Aerosol & mid-latitude & mid-latitude & mid-latitude & mid-latitude & mid-latitude \\
\hline & model & summer & summer & summer & winter & summer \\
\hline
\end{tabular}


Table 3. 6S input parameters from the June 2013 Landsat 8 scene

\begin{tabular}{lll}
\hline Parameter choices & & 6S input file \\
\hline Geometrical conditions & Sensor & 17 (Landsat 8) \\
& Month, day, decimal hour & $6,9,11.51$ \\
& Longitude, latitude & $-8.17,53.085$ \\
& (Decimal Degrees) & \\
Atmospheric model & Atmospheric profile & 2 (mid-latitude summer) \\
& Aerosol model & 2 (maritime) \\
& Optical depth at 550 nm & 0.131 \\
Target and sensor altitude & Target elevation (-km a.s.l.) & -0.137 \\
& Satellite level (-km a.s.l) & -705 \\
& Band number & 118 (Landsat 8 red band) \\
\hline
\end{tabular}


Figure 1

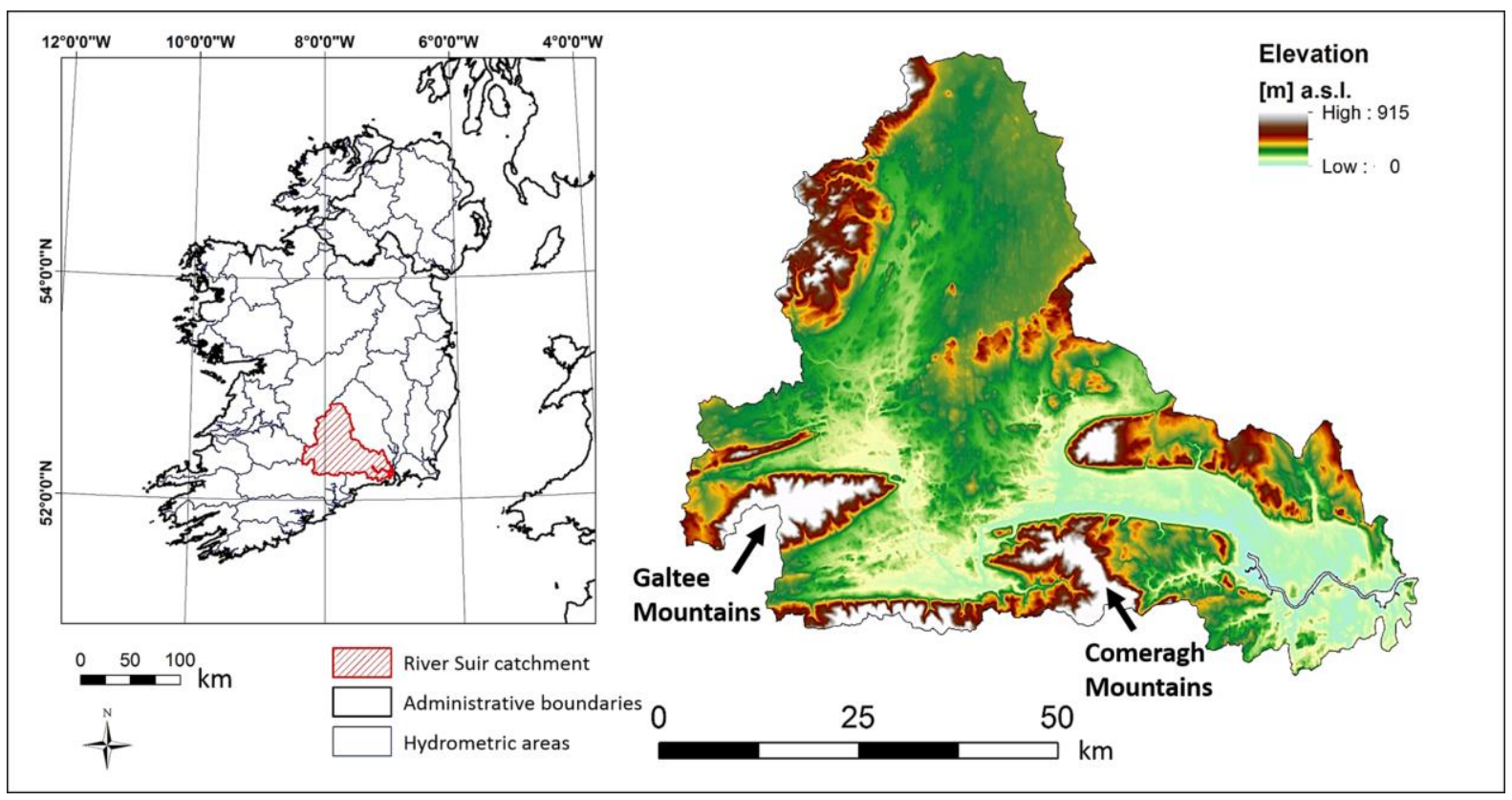


Figure 2

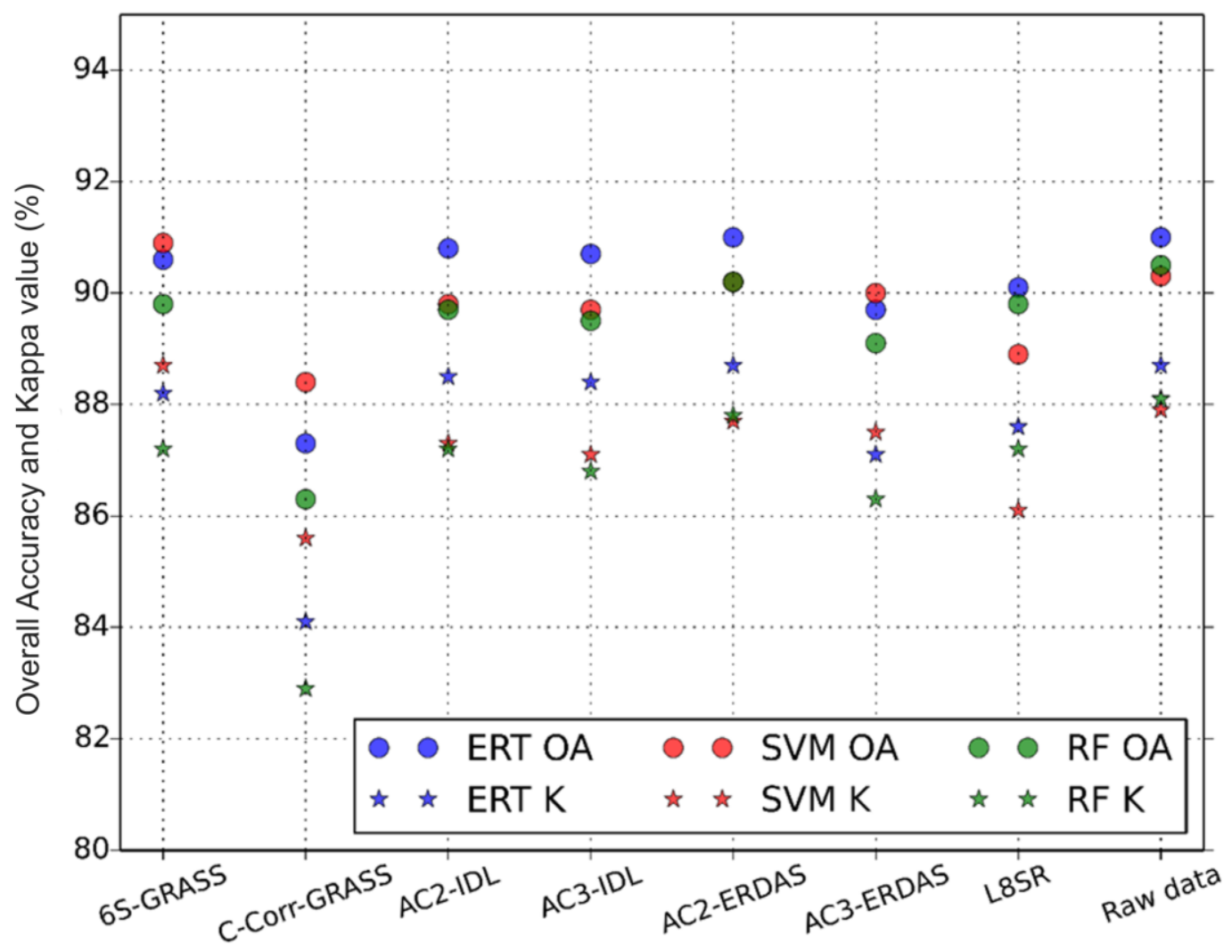


Figure 3
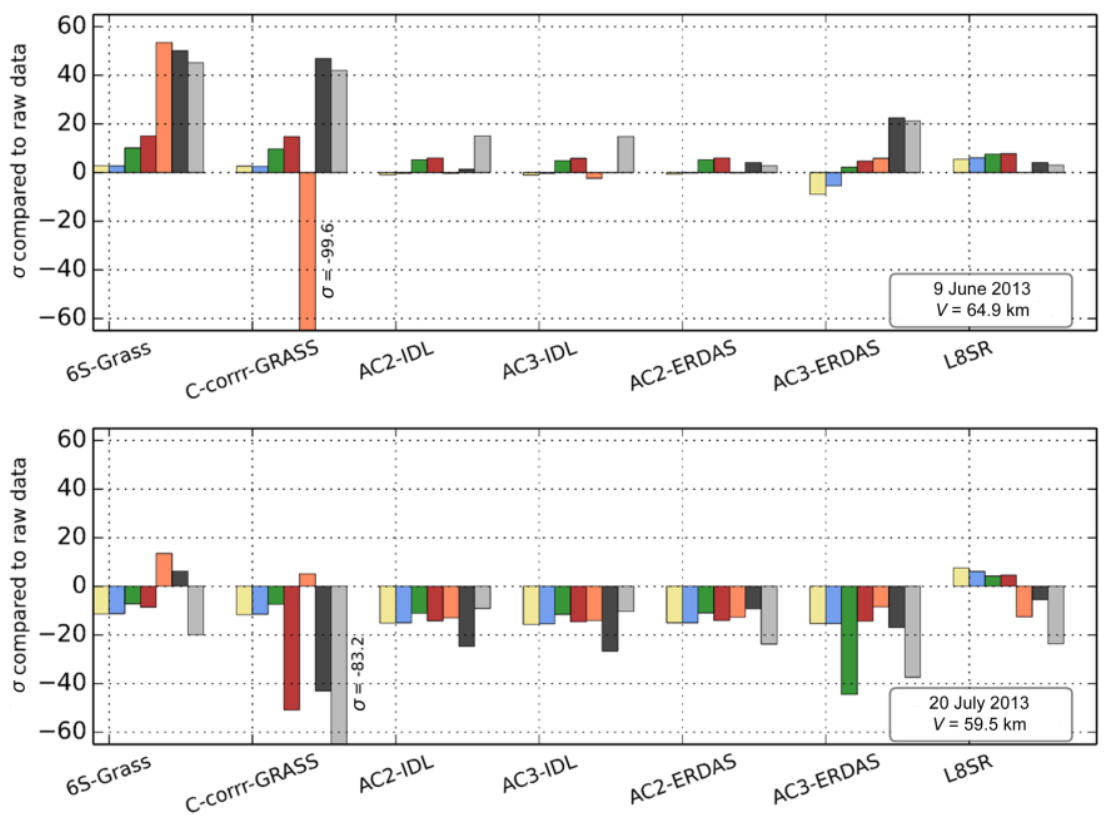

435-451nm (Coastal)
$452-512 \mathrm{~nm}$ (Blue)
$533-590 \mathrm{~nm}$ (Green)
636-673nm (Red)
850-879nm (NIR)
1566-1651nm (SWIR1)
2107-2294nm (SWIR2)


Figure 4
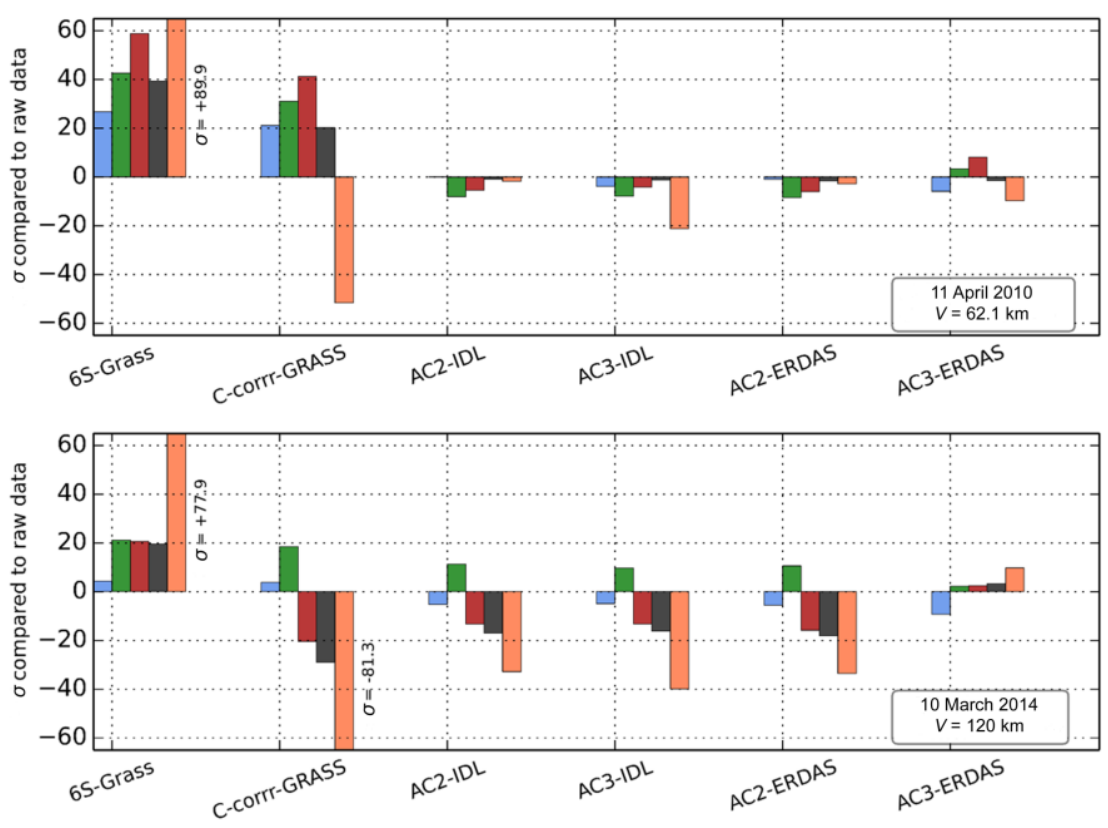

440-510nm (Blue)

520-590nm (Green)

630-685nm (Red)

690-730nm (Red Edge)

760-850nm (NIR) 